\title{
EDITORIAL
}

\section{Should You Trust Your Money to a Robot?}

\author{
Vasant Dhar \\ Editor-in-Chief
}

\begin{abstract}
Financial markets emanate massive amounts of data from which machines can, in principle, learn to invest with minimal initial guidance from humans. I contrast human and machine strengths and weaknesses in making investment decisions. The analysis reveals areas in the investment landscape where machines are already very active and those where machines are likely to make significant inroads in the next few years.
\end{abstract}

Computers are making more and more decisions for us, and increasingly so in areas that require human judgment. Driverless cars, which seemed like science fiction until recently, are expected to become common in the next 10 years. ${ }^{1}$ There is a palpable increase in machine intelligence across the touchpoints of our lives, driven by the proliferation of data feeding into intelligent algorithms capable of learning useful patterns and acting on them. We are living through one of the greatest revolutions in our lifestyles, in which computers are increasingly engaged in our lives and decision making, to a degree that it has become second nature. Recommendations on Amazon or auto-suggestions on Google are now so routine, we find it strange to encounter interfaces that don't anticipate what we want. The intelligence revolution is well under way, with or without our conscious approval or consent. We are entering the era of intelligence as a service, with access to building blocks for building powerful new applications.

A natural question to ask is how we should be thinking about the role of computers in managing our financial lives. Should we trust our money to a robot? In an era of big data and machines to make sense of it all, do machines have an inherent advantage over humans? There is a surge of interest in artificial intelligence for financial prediction and risk management. Should we pay attention? Or is this an area where human judgment and input is always essential?

There's a lot at stake. It is estimated that global assets under management will reach $\$ 100$ trillion by 2020 from their current level of $\$ 70$ trillion, with roughly al- most half of this asset base in the United States. ${ }^{2}$ If we assume a net revenue of 30 basis points, ${ }^{3}$ this translates into a $\$ 300$ billion market.

Financial experts can serve an important role in defining our financial objectives and tailoring our investments to our profiles. For example, they apply guidelines such as steering older people with limited means towards less risky investments, provide advice on diversification, implications of changing tax laws and regulation, and more. However, time and time again, the evidence suggests that humans' record in picking investments is quite poor. There is a lot of academic literature on human biases in decision making which result in irrational decisions, ${ }^{4}$ misguided overconfidence, and incorrect attribution $^{5}$ that arguably makes us bad investors. In a class on systematic trading strategies that I have been teaching for over 10 years at New York University, most students admit that despite their diligence and experience they typically do worse than the market, often citing emotion and complexity as reasons for their underperformance. Consistent with the literature, they report trading more than they should, ${ }^{6}$ holding losers too long hoping for a rebound, and exiting winners too quickly out of fear of giving back gains. ${ }^{7}$

How does one explain the performance of legendary managers such as Stanley Drukenmiller, George Soros, and Warren Buffet? Druckenmiller attributes his early career success from recognizing a few special investment opportunities. The first was the overthrow of the Shah of Iran, which argued for rising oil prices, and making a concentrated bet in going long oil and defense stocks. His and Soros' best-known trade, 


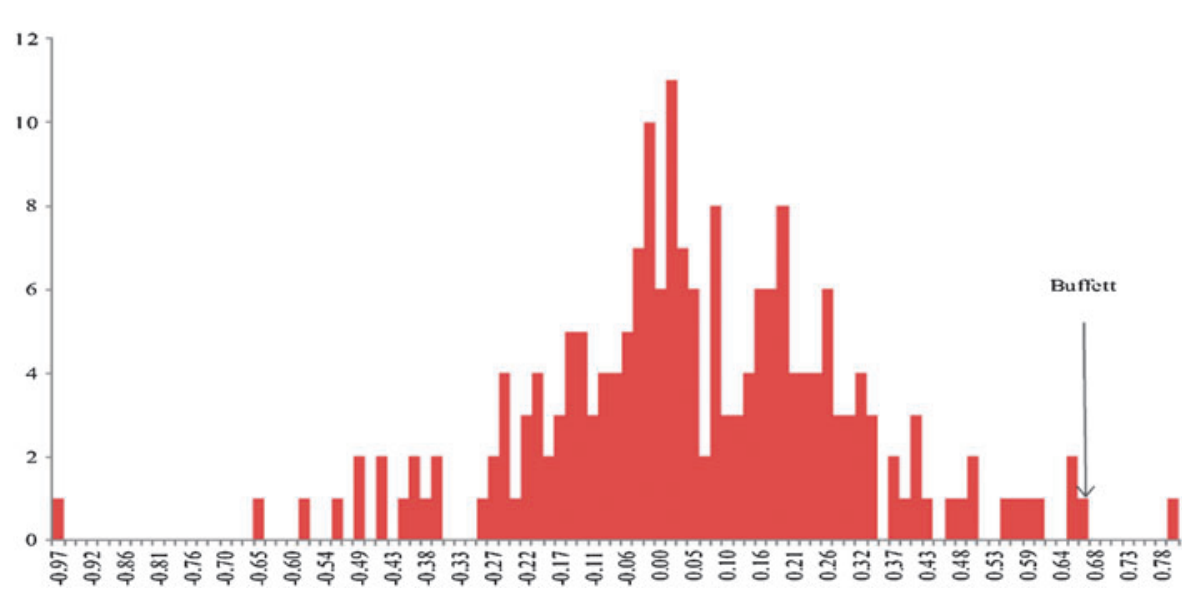

FIG. 1. Information ratio distribution of mutual fund managers with more than 30 years of performance between 1926 and 2011.

however, was selling the British Pound and buying the Deutsche Mark in September 1992. This was based on the very different stances of two central banks driven by different economic states of their underlying economies, but where the two currencies were linked and something "had to give"-in this case, their linkage that forced down the British Pound.* While one might uncharitably attribute this specific trade to luck, Druckenmiller's subsequent record of zero losing years out of 30 makes it quite apparent that his prescience was exceptional in recognizing special economic situations with large upside with limited risk.

"Buffet's alpha," in contrast, which has been long lived, derives from a more systematic and definable strategy of buying cheap, safe, quality stocks and the use of leverage obtainable to him at favorable terms through his insurance businesses and other sources. ${ }^{8}$ Figure 1 puts Buffet's performance in perspective.

The figure shows the information ratios ${ }^{\dagger}$ of all actively managed equity funds in the Center for Research of Securities Prices (CRSP) mutual fund database with at least 30 years of history between 1926 and $2011 .^{8}$ Buffet's Information Ratio of roughly 0.7 stands out in this co-

*Britain had entered the European Exchange Rate Mechanism (ERM) in October 1990 , which forced members to maintain currencies in a narrow range relative to the point at which they entered the mechanism. In 1992, the postunification Bundesbank was focusing single-mindedly on curbing inflation by raising rates, forcing Britain as part of the ERM to keep rates high same even as it was going into a recession with its currency under selling pressure. This was the setup where something had to correct. It played out by Britain being forced to exit the ERM.

This is defined as the ratio of annualized average excess return over a benchmark (such as the S\&P500) divided by the standard deviation of these returns. Buffet's alpha is reported over the S\&P500.

www.crsp.com hort and is roughly double that of the S\&P500, which hovers in the range of 0.3 to 0.4 . Most managers underperform the market, a pattern that has been noted in industry and academic reports over the years. Clearly, it is difficult to outperform a carefully constructed basket representing the healthiest companies across the economy. While human genius does exist, it is very hard to find the next Druckenmiller or Buffett. Might one have more success finding a good robot?

Not surprisingly, the answer is that it depends on the adequacy of various types of data. The greater the number of independent examples to learn from and the greater the "signal" in the data, the more likely that a robot will do well. To illustrate how this plays out in in investing, Figure 2 sketches out the investment landscape in terms of the holding periods of managers, and divides this into roughly three investment styles-less than a day, days to weeks, and months to years.

On the left is the high frequency space, which is dominated by big data and fast machines. Gone are the days of day traders staring feverishly at screens to seize shortlived opportunities. At this time scale, there are large numbers of independent data samples for intelligent algorithms to discover repeated and exploitable patterns. Decisions are very frequent, in the hundreds or thousands per day, but only a small amount of risk can be allocated to each decision because the limited liquidity in the market severely constrains the size of each decision. In other words, while the signal quality is high, the size of the opportunity in this space is low.

At the other end of the spectrum are long-term investors. The basis for investment decisions tends to 


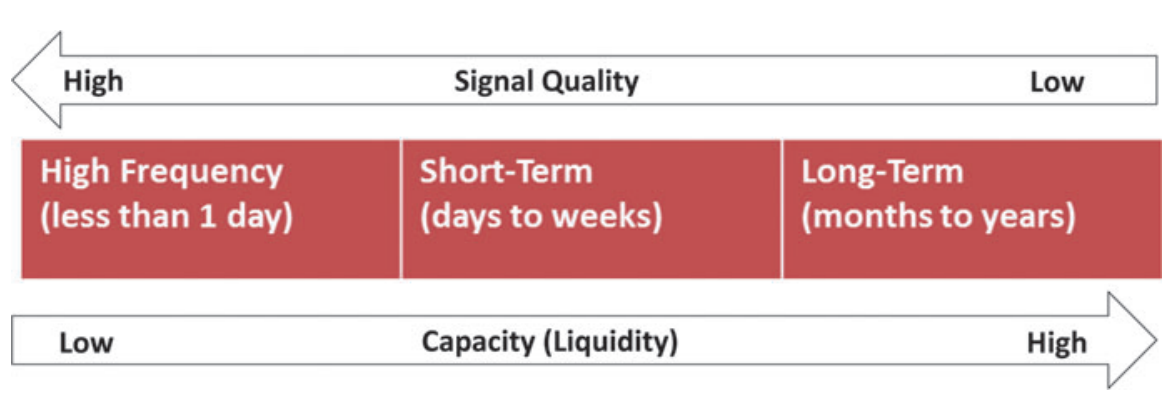

FIG. 2. Investment landscape by holding period.

be fundamental economic factors such as inflation, growth, employment, and central bank posture, or a more systematic basis such as that of Buffet. It takes a long time to know whether a strategy or view works. There are too many unknowns and exogenous factors that can impact outcomes. Other than the legends mentioned earlier whose skills are difficult to doubt, it is generally difficult to distinguish skill from luck. At the same time, the lack of data of sufficiently high frequency makes this a difficult terrain for machines, although it is possible that a "BuffettBot" that implements his core philosophy might well exist in the future.

The space in the middle has a much larger and growing set of opportunities than in the long-term space but a more modest level of signal depending on the specific opportunity. In contrast to the "long only" types of strategies followed by most fund managers in the long-term space where it is difficult to beat the performance of the healthiest companies, managers can target other opportunities such as the "long/short" equities space where identifying relatively "unhealthy" companies is equally important. Other opportunities include "events" (such as earnings releases, major initiatives, etc.); identifying "distressed" situations; focusing on specific sectors such as healthcare, banking, etc., and other liquid spaces such as financial futures on equity markets, currencies, bonds, and commodities.

Robotic investing has already made significant inroads into the various opportunity sets represented in the middle of Figure 2. In this space, decisions can be frequent enough to warrant a systematic model of decision making without subjecting it to human bias or emotion. In the mid-1990s I began to explore this space inside a Wall Street proprietary trading unit, using machine learning techniques as a tool to help discover actionable trading patterns in the data. This process still contained multiple subjective decision points that introduced the well-documented human weakness and biases. As we evolved over time, we developed a meta process that automated the entire process from discovery to action and monitoring, essentially creating an intelligent robot.

Our expectation was that the robot would have several advantages over humans despite lacking our common sense and domain knowledge and intuition. A central appeal was that an unemotional data-driven process would be "objective" in that it would stay true to its basis encoded in an algorithm. We also chose to make the machine "adaptive," able to learn from additional data as they become available in order to deal gracefully with the reality of market evolution. The machine, called AQT for "automated quant trading," trades exchangetraded futures contracts and went live in August 2009 on Deustche Bank's dbSelect platform, which contains roughly 100 futures trading programs that fall in the middle part of Figure $2 .^{\S}$ Of these, 43 futures programs have a performance history of at least 5 years. Their average information ratio before fees is roughly $0.6^{\star *}$ (net of all transactions costs, but before fees), with two-thirds of the programs in the range of 0.3 to 0.9 , and the AQT robot just north of the range as of April 2015.

From their description of the programs, it is not clear what proportion of these programs are robotic, human, or hybrid. It would be presumptuous to suggest that the information ratios of the top systematic programs in this category makes them the robotic equivalent of the human superstars, but the record is not discouraging. There is also some recent evidence that algorithmic approaches performed well in $2014,{ }^{9}$ but it will be some time before we have enough data to evaluate the success

SPerformance is calculated on a daily basis for all programs on the platform and published monthly.

**In this case the benchmark is zero since these futures strategies seeks an absolute return. AQT's Information Ratio is 0.96 . 
of data driven approaches in the various opportunities of the investment landscape. As a guiding principle, however, a robot should be considered seriously in situations where there is sufficient data from which it can learn, and the frequency of decisions favors unemotional systematic decision making over human judgment that is often saddled by emotion and irrational bias. These areas of opportunity correspond to the left and middle spaces of Figure 2. However, it is important to stress that a machine is unlikely to recognize exceptional situations such as a budget crisis or acts of nature where humans must ultimately decide whether to take a robot offline or reduce its risk exposure temporarily.

One trend appears quite certain: as the data emanating from the markets and society continues to increase, artificial intelligence approaches will grow and offer alternative ways of investing. Robots are more likely to be embraced by millenials than by the baby boomer generation that abdicated investing mostly to human advisors. A proliferation of robots does raise the tantalizing possibility of machines competing with other machines in the way humans have done in the past. Arguably, this has begun already. On February 27, 2015, Ray Dalio of Bridgewater Associates, a \$160 billion hedge fund, announced a deep commitment to artificial intelligence as a basis for investment decision making. ${ }^{10}$ Referring to the Bridgewater initiative, the $\mathrm{CEO}$ of a major recruitment firm remarked, "Machine learning is the new wave of investing for the next 20 years and the smart players are focusing on it." The race to build "big data machines" in financial investing seems to be well under way.

\section{References}

1. Kaufman AC. Elon Musk: We'll Have Driverless Cars By 2023. October 15, 2014. Available online at: www.huffingtonpost.com/2014/10/15/tesladriverless-cars_n_5990136.html?ir=India\&adsSiteOverride $=$ in

2. PricewaterhouseCoopers LLP. PwC: Global assets under management (AuM) to exceed $\$ 100$ trillion by 2020 with nearly 50 percent residing in North America. February 10, 2014. Available online at www.pwc.com/us/ en/press-releases/2014/pwc-global-assets-under-management.jhtml

3. Britton D. Asset Management Growth Belies Systemic Decline in Revenue. WealthManagement.com. July 16, 2014. Available online at http:// wealthmanagement.com/asset-management/asset-managementgrowth-belies-systemic-decline-revenue

4. Kahneman D, Tversky A. On the psychology of prediction. Psychol Rev $1973 ; 80: 237-251$.

5. Odean T, Gervais S. Learning to be overconfident. Rev Financ Stud 2001; 14:1-27.

6. Odean T, Barber B. Online investors: do the slow die first? Rev Financ Stud 2002; 15:455-487.

7. Shefrin $\mathrm{H}$, Statman $\mathrm{M}$. The disposition to sell winners too early and ride losers too long: theory and evidence. J Financ 1985; 40:777-790.

8. Frazinni A, Kabiller D, Pedersen L. Buffet's alpha. NBER working paper 19681. Cambridge, MA: National Bureau of Economic Research, November 2013. Available online at www.nber.org/papers/w19681

9. Stevenson A. For top 25 Hedge fund managers, a difficult 2014 still paid well. New York Times, May 5, 2015. Available online at www.nytimes.com/ 2015/05/05/business/dealbook/top-25-hedge-fund-managers-took-bad14-all-the-way-to-the-bank.html?smid = pl-share\&_r $=0$

10. Feloni R. Billionaire hedge fund manager Ray Dalio - who encourages employees to see their team as a 'machine' - is building an artificial intelligence unit. Business Insider, February 7, 2015. Available online at www.businessinsider.com/artificial-intelligence-team-at-bridgewater2015-2

Cite this article as: Dhar V (2015) Should you trust your money to a robot? Big Data 3:2, 55-58, DOI: 10.1089/big.2015.28999.vda

\section{Abbreviation Used}

$\mathrm{ERM}=$ exchange rate mechanism 